\title{
Diet during Rotavirus Enteritis Affects Jejunal Permeability to Macromolecules in Suckling Rats
}

\author{
ERIKA ISOLAURI, MINNA KAILA, TAINA ARVOLA, HELI MAJAMAA, IMMO RANTALA, \\ ELINA VIRTANEN, AND HEIKKI ARVILOMMI \\ University of Tampere, Department of Clinical Sciences, Tampere, Finland [E.I., M.K., T.A., H.M., I.R.]; and \\ National Public Health Institute, Turku, Finland [E.V., H.A.]
}

\begin{abstract}
We studied the influence of diet during diarrhea on gut mucosal barrier in a suckling rat model. Rat pups were inoculated with IDIR virus (a group B rotavirus) at $10 \mathrm{~d}$ of age. Beginning $2 \mathrm{~d}$ postinfection, in addition to maternal milk, group $\mathrm{CM}$ received a daily gavage of cow milk and group GG received Lactobacillus casei strain GG, a human strain previously shown to survive the passage through the gastrointestinal tract and temporarily colonize the gut. Group CMGG received a combination of these, and control animals were gavaged with tap water. At $21 \mathrm{~d}$ of age, jejunal absorption of intact and degraded horseradish peroxidase (HRP) in Ussing chamber was markedly higher in IDIR virus-infected than in noninfected controls. In the two groups gavaged with cow milk, group $\mathrm{CM}$ and group CMGG, the numbers of specific antibody-secreting cells (enumerated by the solid-phase enzyme-linked immunospot assay) against $\beta$-lactoglobulin were significantly higher than in the groups that had not received cow milk. In parallel with immune system activation, a statistically significant increase in the absorption of intact HRP (mean and $95 \%$ confidence interval, $\mathrm{ng} \times \mathrm{h}^{-1} \times \mathrm{cm}^{-2}$ ) was detected: group CM, 302 (155, 586); group CMGG, 174 (56, $545)$; infected controls, $121(57,257)$; and group GG, 44 $(8,254)$. A decrease in the uptake of intact HRP $(F=$ 3.64, $p=0.06)$ and degraded HRP $(F=9.50, p=0.004)$ was associated with the introduction of $L$. casei GG to the diet, irrespective of coexposure to cow milk. These results indicate that feeding cow milk amplifies and intestinal implantation of lactobacilli may counteract rotavirus infection-associated intestinal dysfunction. They further suggest that milk fermented with lactic acid bacteria that are able to colonize the gut may prove near-optimal in dietary management of acute gastroenteritis. (Pediatr Res 33: 548$553,1993)$
\end{abstract}

\section{Abbreviations}

Abbreviations

ANOVA, analysis of variance

$G$, total ionic conductance

HRP, horseradish peroxidase

$I_{S C}$, short-circuit current

$\mathrm{PD}$, potential difference

sASC, specific antibody-secreting cells

ELISPOT, enzyme-linked immunospot
Gut mucosa is a barrier that selectively excludes a variety of antigenic macromolecules. Rotavirus infection leads to malfunction of this barrier. Rotaviruses invade the terminally differentiated mature enterocytes in the small intestinal villi, causing watery diarrhea and malabsorption of nutrients $(1,2)$. The infected enterocytes are replaced by immature crypt-type cells, in which the uptake of proteins and the rate of endocytosis are elevated (2-4). Such dysfunction of the mucosal barrier results in defective handling of antigens encountered by the enteric route, reflected in transiently enhanced permeation of macromolecules across the intestinal epithelium (5-7). The increase in antigenic load may evoke immune responses and sensitization to dietary antigens.

The role of rotavirus as a major cause of acute gastroenteritis in infants is undisputed $(2,8)$, whereas considerable controversy exists as to the optimal diet of non-breast-fed patients who have rotavirus gastroenteritis $(9,10)$. We have previously shown that rapid refeeding with a mixed diet containing cow milk promotes recovery from diarrhea (11). A further reduction in the duration of rotavirus diarrhea was effected by introduction of fermented milks to the diet $(12,13)$. Fermented dairy products may be beneficial, not only because of low lactose content, but also because of reestablishment of intestinal microflora, an important component of the gut mucosal barrier (14). Lactobacillus casei strain GG is a newly isolated strain of human origin. This strain was chosen because it has been shown to possess certain qualities that are considered essential for oral bacteriotherapeutic agents, such as survival through the gastric milieu, adherence to intestinal epithelial cells, and colonization of the gut $(14,15)$.

In this article, we have investigated in a suckling rat model the influence of rotavirus infection and dietary management of acute gastroenteritis on the gut mucosal barrier. Specifically, the question of the effect of lactic acid bacteria on nonspecific macromolecular absorption was addressed.

\section{MATERIALS AND METHODS}

Animals and Experimental Design. The suckling rat model of rotavirus gastroenteritis was used, because the timing and pattern of gut development are well established in rats (16-18). Gut closure is extended until the age of $21 \mathrm{~d}$, and a decline in the absorption of intact HRP coincides with this process $(18,19)$.

Male and female Wistar rat pups were studied at the age of 21 d. Birth day was taken as d 0 . The animals were reared at a density of 12 pups/dam in a conventional experimental animal laboratory with barriers. The pups were allowed to suckle throughout the period of experimentation (Fig. 1). On d 21, 24 $\mathrm{h}$ after the last administration of the experimental feedings, the animals were anesthetized with intraperitoneal pentobarbital (30-40 mg/ $\mathrm{kg}$ ), decapitated, and exsanguinated. Blood was collected in heparinized tubes. The animals were then surgically prepared for the Ussing chamber and the morphologic studies. The Ussing chamber studies were carried out in an additional six infected controls that were $24 \mathrm{~d}$ old.
Received April 14, 1992: accepted January 6, 1993.

Correspondence and reprint requests: Dr. Erika Isolauri, Department of Clinical Sciences, University of Tampere, P. O. Box 607, 33101 Tampere, Finland.

Supported by the Foundation for Nutrition Research, Paulo Foundation, and Emil Aaltonen Foundation. 


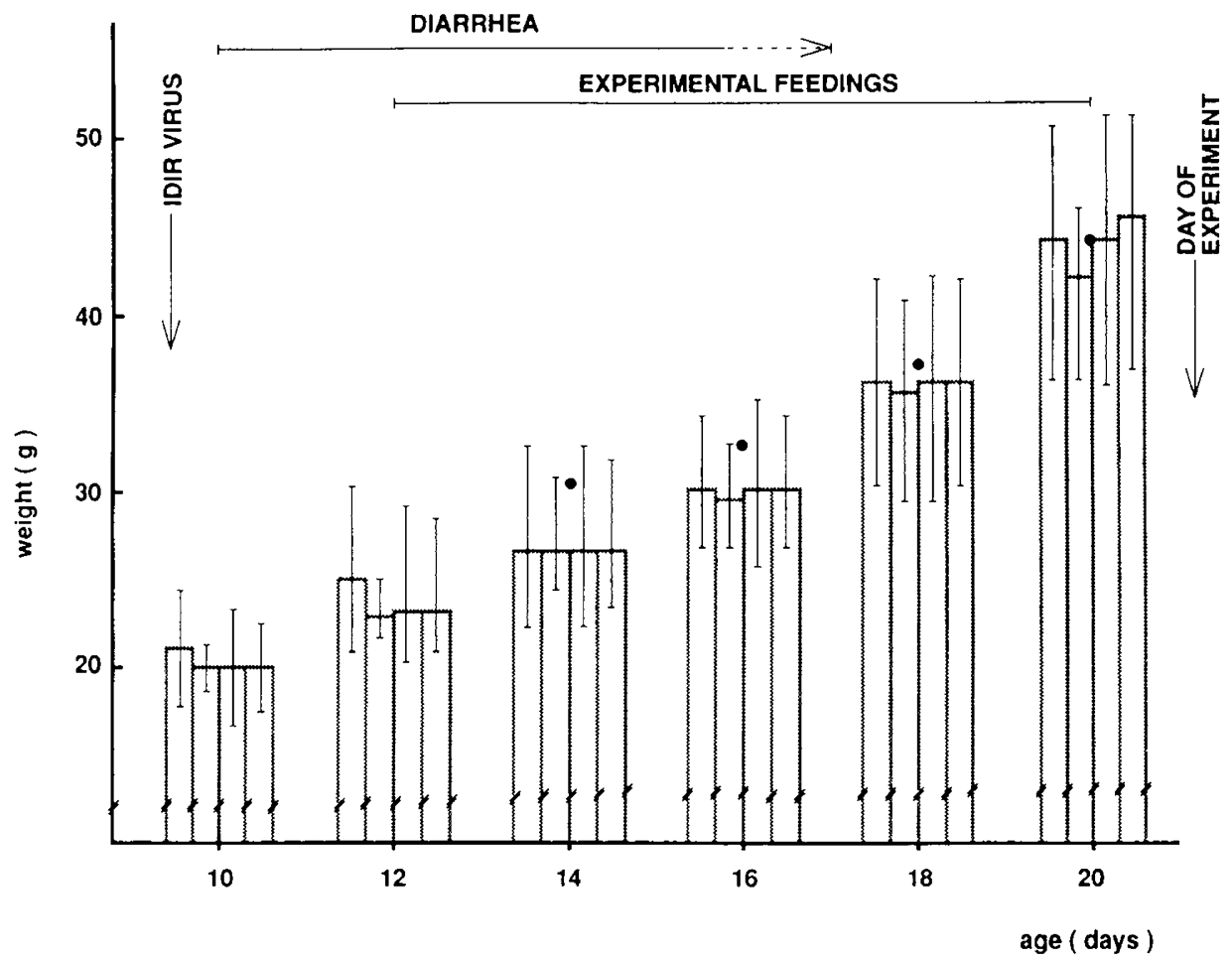

Fig. 1. Experimental design, duration of diarrhea, and weight gain over the experimental feeding period in rat pups infected with the IDIR virus. First column, infected controls; second column, gavaged with the lactobacilli (group GG); third column, gavaged with cow milk (group CM); and fourth column, gavaged with both the lactobacilli and cow milk (group CMGG). Filled circles represent mean weights of noninfected controls.

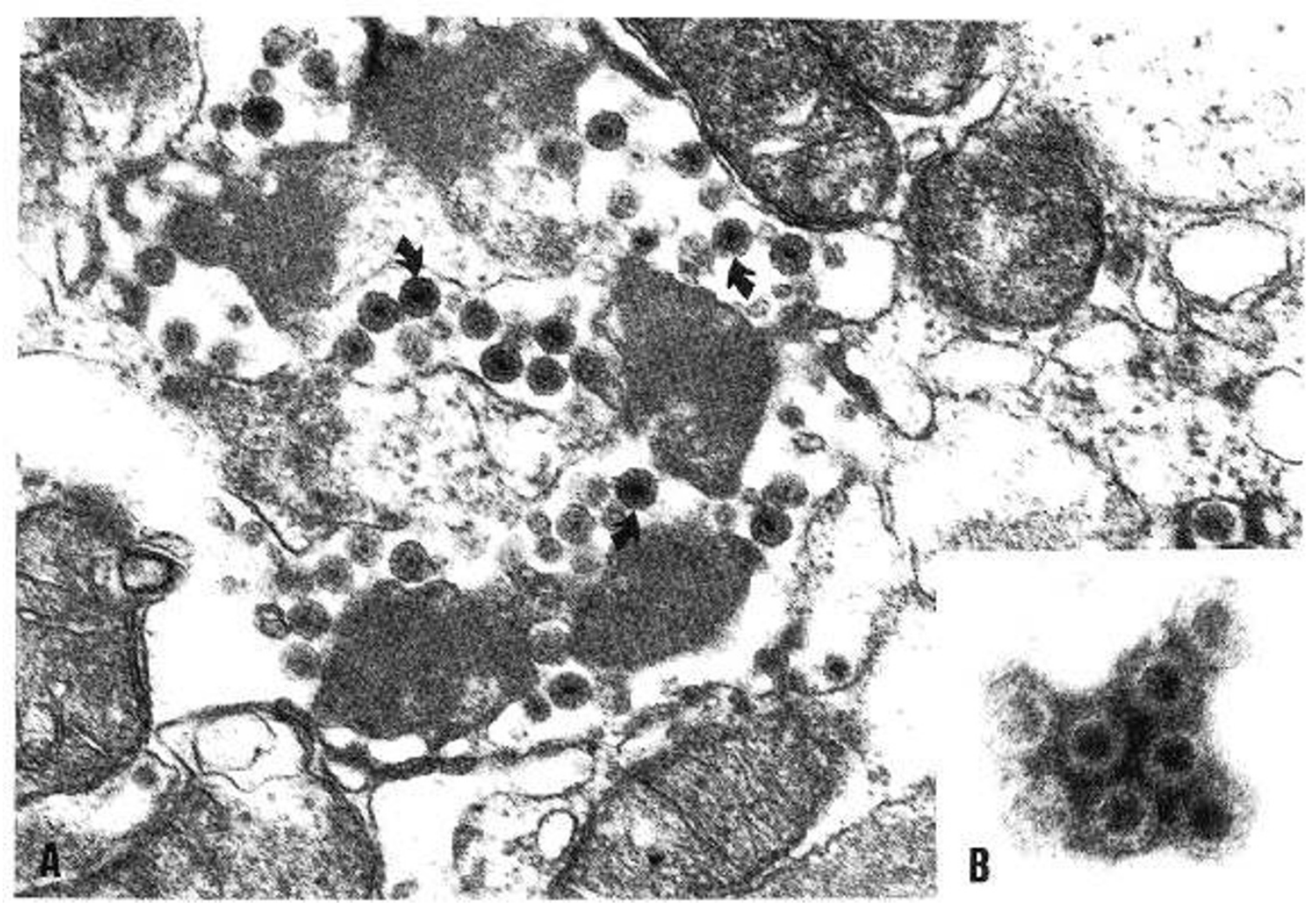

Fig. 2. $A$, Rotavirus particles (arrows) are seen in dilated endoplasmic reticulum of an epithelial cell $(\times 48000)$. $B$, Negatively stained rotaviruses in feces $(\times 120000)$.

The study was approved by the Institute of Animal Care and Use at the University of Tampere.

Rotavirus Infection. A stock of IDIR virus-containing inoculum was prepared as previously described (20). This group B rotavirus was a kind gift of Dr. Steven L. Vonderfecht. The rat pups, at $10 \mathrm{~d}$ of age, were given $10 \mu \mathrm{L}$ of the virus stock solution. In previous studies, it was shown that rat pups are vulnerable to IDIR virus at this age. To avoid virus cross-contamination, the experimentally infected rats were housed in a building separated from the laboratory and from the noninfected animals. 

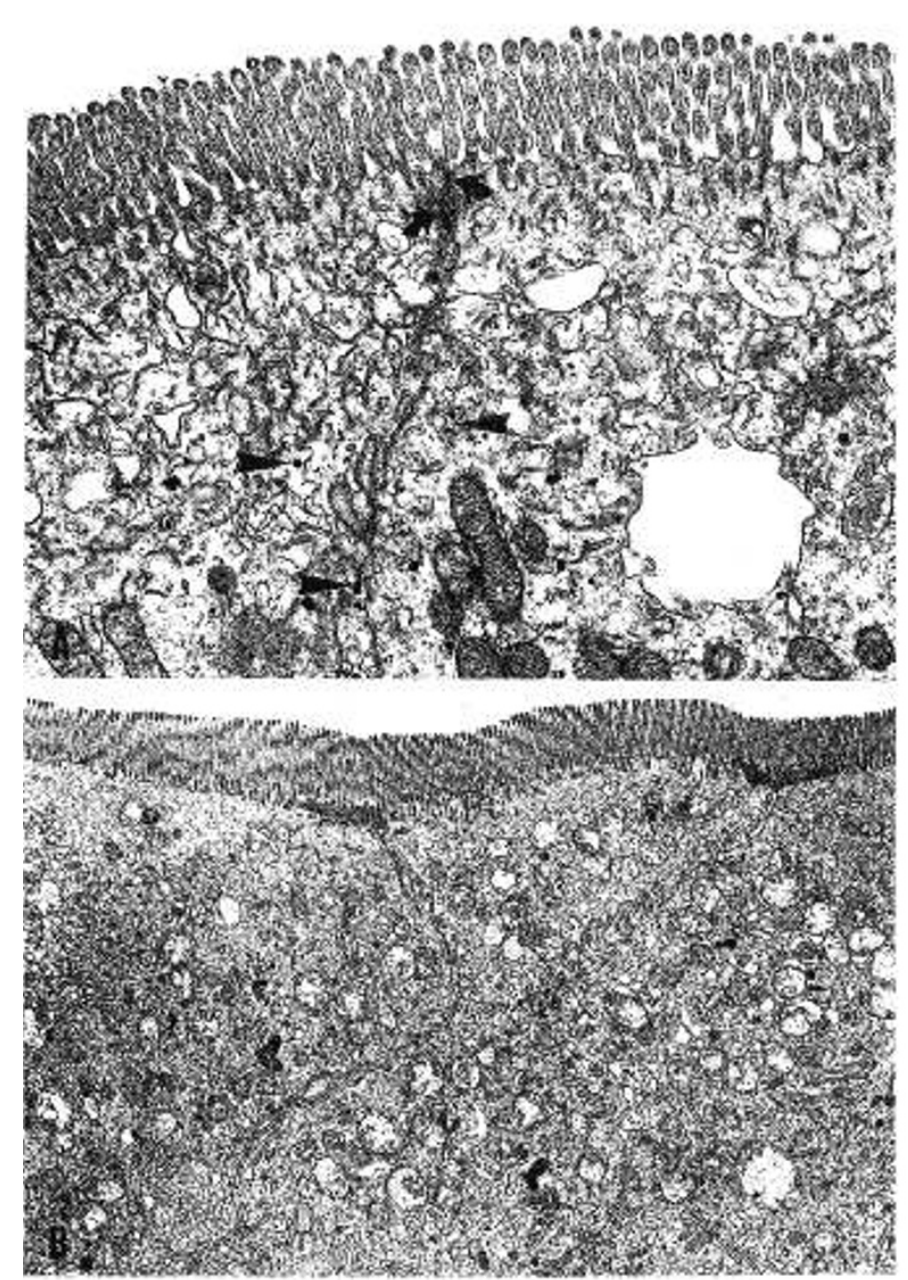

Fig. 3. A, Two adjacent epithelial cells of an IDIR virus-infected rat pup on $\mathrm{d} 11$ (d 1 postinfection). Cell junctions are indicated by arrows and virus particles by arrow heads $(\times 14500)$. $B$, Intact epithelium of an IDIR virus-infected rat pup on $\mathrm{d} 21$ (day of experiment) $(\times 4500)$.

It has been shown that the number of IDIR viruses reaches a maximum $1 \mathrm{~d}$ after experimental infection (20). Six pups were killed on d 11 (d 1 postinfection). After laparotomy, small pieces of ileum were excised for electron microscopic study and placed in $2 \%$ glutaraldehyde in $0.1 \mathrm{~mol} / \mathrm{L}$ phosphate buffer $(\mathrm{pH} \mathrm{7.4)}$ for $2 \mathrm{~h}$ at $4^{\circ} \mathrm{C}$. After being washed in phosphate buffer, the specimens were postfixed in $\mathrm{OsO}_{4}$ and conventionally processed into Epon blocks. Ultrathin sections were stained with lead citrate and uranyl acetate. Fecal samples were obtained from 12 pups. The samples were diluted with PBS, and negative staining with $2 \%$ aqueous ammoniummolybdate was carried out on electron microscopic grids coated with Formvar.

Experimental Feedings. On d 12 (d 2 postinfection), the pups were divided into four feeding groups until $21 \mathrm{~d}$ of age. Three pups per litter were allocated to each group. All pups remained with the mother and were breast-fed with maternal milk. The dams' diet (standard rodent food, EWOS Ab, Södertälje, Sweden) was free of any cow milk antigens. In addition to breast milk, group CM received a daily gavage of cow milk proteins $(1.0 \mathrm{mg}$ / g body weight/d), group GG received $L$. casei strain GG $(3 \times$ $10^{8-9}$ colony-forming units/d), and group CMGG received a combination of these. In another investigation, it was demonstrated that the strain is recovered from the feces of rat pups by this feeding schedule (Isolauri E, Majamaa H, Arvola T, Rantala I, Virtanen E, Arvilommi $\mathrm{H}$, unpublished observations). The control animals were gavaged with tap water. The timing of the daily gavages was planned so that an interval of $24 \mathrm{~h}$ elapsed between two subsequent feedings as well as between the last feeding and the experiments on $\mathrm{d} 21$.

Ussing Chamber Studies. Reagents. The reagents used in Ussing chamber studies were HRP (Sigma type VI, Sigma Chemical Co., St. Louis, MO; molecular weight 40000 ) and ${ }^{125}$ I-HRP, iodinated using $500 \mu \mathrm{Ci}$ of ${ }^{125} \mathrm{I} / 1.0 \mathrm{mg}$ HRP according to the method of Markwell (21). All reagents were dissolved in Ringer solution ( $\mathrm{pH} 7.4$ ) containing, in mM: $140 \mathrm{Na}, 5.2 \mathrm{~K}, 1.2 \mathrm{Ca}, 1.2$ $\mathrm{Mg}, 120 \mathrm{Cl}, 25 \mathrm{HCO}_{3}, 2.4 \mathrm{HPO}_{4}$, and $0.4 \mathrm{H}_{2} \mathrm{PO}_{4}$.

Procedure. The abdominal cavity was opened so a segment of jejunum $10 \mathrm{~cm}$ distal of the ligament of Treitz could be removed. The segment was rinsed with Ringer solution, opened, and laid as a flat sheet on a Millipore filter. The tissue was mounted on the filter in an Ussing chamber with an exposed area of 0.15 $\mathrm{cm}^{2}$. Silicone paste was used to minimize edge damage. The tissue was bathed on mucosal and serosal sides with $1.5 \mathrm{~mL}$ of Ringer solution that was maintained at $37^{\circ} \mathrm{C}$ and oxygenated $\left(95 \% \mathrm{O}_{2}, 5 \% \mathrm{CO}_{2}\right)$.

The solutions bathing the mucosal and serosal sides were connected via $3 \mathrm{M} \mathrm{KCl}$ agar bridges to calomel electrodes for measurement of transepithelial PD and to $\mathrm{Ag}-\mathrm{AgCl}$ electrodes for the passage of current through the system. Fluxes were measured under open-circuit conditions. $G$ was regularly assessed by passing a $10-\mu \mathrm{A}$ current through the preparation. $\mathrm{I}_{\mathrm{SC}}$ was then calculated, taking into account the fluid and filter resistance.

HRP was added to the mucosal compartment at a final concentration of $0.4 \mathrm{mg} / \mathrm{mL}$ to quantitate the absorption of the protein in its intact form. ${ }^{125}$ I-HRP was used as a tracer for the quantitation of total protein absorption. For $110 \mathrm{~min}, 800-\mu \mathrm{L}$ samples were taken from the serosal side at 20-min intervals and replaced by fresh Ringer solution. Total HRP absorption was assessed by counting the radioactivity of $500-\mu \mathrm{L}$ aliquots from the samples. The rate at which intact HRP was transferred to the serosal compartment was assessed by measuring the activity of HRP using a modified version of Maehly and Chance (22), with $\mathrm{H}_{2} \mathrm{O}_{2}$ as the substrate and $3,3^{\prime}$-dimethoxybenzidine as the dye. A previous Ussing chamber study showed by gel chromatography that only the intact fraction of HRP has enzymatic activity (23). The absorption of degraded HRP was then calculated by subtracting the absorption of intact HRP from total protein absorption. The mucosal-to-serosal transport remained constant be-

Table 1. Electrical parameters: PD, G, and ISC of jejunal tissues measured during HRP transport studies in rat pups experimentally infected with IDIR virus and gavaged with either lactobacilli (group GG) or cow milk (group CM) or both lactobacilli and cow milk (group CMGG) and in noninfected controls*

\begin{tabular}{|c|c|c|c|c|c|c|}
\hline & $\begin{array}{c}\text { Noninfected } \\
\text { controls }\end{array}$ & $\begin{array}{l}\text { Infected } \\
\text { controls }\end{array}$ & Group GG & Group CM & Group CMGG & ANOVA \\
\hline $\mathrm{PD}(\mathrm{mV}) \dagger$ & $\begin{array}{c}0.5 \\
{[0.2,1.2]}\end{array}$ & $\begin{array}{c}0.2 \\
{[0.1,1.0]}\end{array}$ & $\begin{array}{c}0.5 \\
{[0.2,1.0]}\end{array}$ & $\begin{array}{c}0.1 \\
{[0.1,0.4]}\end{array}$ & $\begin{array}{c}0.2 \\
{[0.1,0.6]}\end{array}$ & $\begin{array}{l}F=1.39 \\
p=0.25\end{array}$ \\
\hline $\mathrm{G}\left(\mathrm{mSv} / \mathrm{cm}^{2}\right) \dagger$ & $\begin{array}{c}11.9 \\
{[6.7,21.2]}\end{array}$ & $\begin{array}{c}52.3 \\
{[36.2,75.6]}\end{array}$ & $\begin{array}{c}24.3 \\
{[14.4,41.2]}\end{array}$ & $\begin{array}{c}39.8 \\
{[22.4,70.8]}\end{array}$ & $\begin{array}{c}20.4 \\
{[11.7,35.4]}\end{array}$ & $\begin{array}{l}F=4.59 \\
p=0.004\end{array}$ \\
\hline $\mathrm{I}_{\mathrm{SC}}\left(\mu \mathrm{A} / \mathrm{cm}^{2}\right) \dagger$ & $\begin{array}{c}5.8 \\
{[1.9,17.8]}\end{array}$ & $\begin{array}{c}15.4 \\
{[6.1,38.8]} \\
\end{array}$ & $\begin{array}{c}13.3 \\
{[7.8,22.9]} \\
\end{array}$ & $\begin{array}{c}7.8 \\
{[3.9,20.2]}\end{array}$ & $\begin{array}{c}5.7 \\
{[3.3,9.8]}\end{array}$ & $\begin{array}{l}F=1.70 \\
p=0.17\end{array}$ \\
\hline
\end{tabular}

* Data are the mean [95\% confidence interval] steady state values.

$\dagger n=6-13$ per group. 
Table 2. Number of SASC against $\beta$-lactoglobulin (/10 cells) and absorption of intact $H R P\left(n g \times h^{-1} \times \mathrm{cm}^{-2}\right)$ in rat pups experimentally infected with IDIR virus and gavaged with either lactobacilli (group GG) or cow milk (group CM) or both lactobacilli and cow milk (group CMGG) and in noninfected controls*

\begin{tabular}{|c|c|c|c|c|c|c|}
\hline & $\begin{array}{c}\text { Noninfected } \\
\text { controls }\end{array}$ & $\begin{array}{l}\text { Infected } \\
\text { controls }\end{array}$ & Group GG & Group CM & Group CMGG & ANOVA \\
\hline $\mathrm{sASC} \dagger$ & $\begin{array}{c}0.1 \\
{[0.01,0.4]}\end{array}$ & $\begin{array}{c}0.3 \\
{[0.03,2.5]}\end{array}$ & $\begin{array}{c}0.2 \\
{[0.03,1.1]}\end{array}$ & $\begin{array}{c}1.5 \\
{[0.4,6.4]}\end{array}$ & $\begin{array}{c}1.5 \\
{[0.21,10.6]}\end{array}$ & $\begin{array}{l}F=2.37 \\
p=0.06\end{array}$ \\
\hline Intact HRP $\ddagger$ & $\begin{array}{c}14 \\
{[6,32]}\end{array}$ & $\begin{array}{c}121 \\
{[57,257]}\end{array}$ & $\begin{array}{c}44 \\
{[8,254]}\end{array}$ & $\begin{array}{c}302 \\
{[155,586]}\end{array}$ & $\begin{array}{c}174 \\
{[56,545]}\end{array}$ & $\begin{array}{l}F=3.80 \\
p=0.01\end{array}$ \\
\hline
\end{tabular}

* Data are means [95\% confidence intervals].

$\dagger n=10-18$ per group.

$\ddagger n=6-12$ per group.

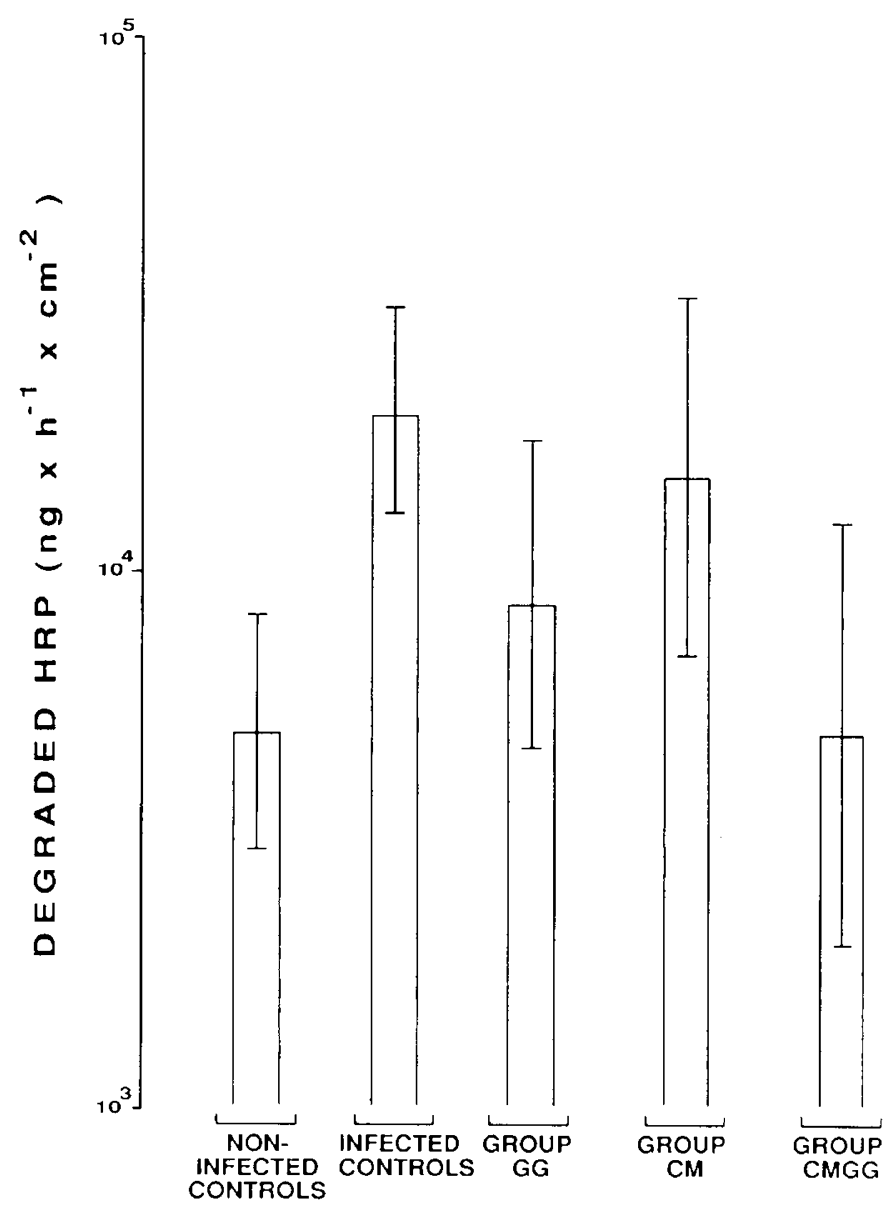

Fig. 4. The absorption of degraded HRP in rat pups experimentally infected with the IDIR virus and gavaged either with the lactobacilli (group GG) or cow milk (group CM) or both the lactobacilli and cow milk (group CMGG). Columns represent geometric means, with $95 \%$ confidence intervals (log scale; $F=3.94, p=0.01$ ).

tween 50 and $110 \mathrm{~min}$. The absorption is reported as a mean of the measurements made during this steady state period.

On d 21, a segment of jejunum adjacent to the one used in the Ussing chamber study was excised and processed for electron microscopy as described above (rotavirus infection).

ELISPOT Assay. The solid-phase ELISPOT assay was used for the enumeration of SASC (24-26). It is a new immunoassay that is thought to give indirect evidence of the gut immunologic events (27-29). The method is based on the maturation cycle of the gut-associated lymphoid tissue-derived lymphocytes (30). After antigen contact, these cells migrate via local lymph nodes and peripheral blood to the mucosal surfaces to secrete antibodies against the priming antigen. This concept is supported by adoptive transfer experiments, in which B-lymphocytes from mucosaassociated lymphoid tissues have been shown to repopulate the mucosa $(31,32)$. The number of the SASC in peripheral blood is maximal $1 \mathrm{wk}$ after intraluminal antigen exposure, several days before the respective antibodies appear $(28,33)$.

Lymphocytes are incubated in antigen-coated microtiter plates. Lymphocytes secreting specific antibodies against these antigens are visualized as colored spots, using enzyme-conjugated antisera followed by an agarose overlay containing the substrate.

Isolation of rat lymphocytes. The procedure described by Keller et al. (34) was followed with a few exceptions. To maximize the yield of lymphocytes, heparinized rat blood was diluted 1:6 in $0.9 \% \mathrm{NaCl}$. The diluted blood was layered over a gradient consisting of $70 \%$ and $60 \%$ Percoll (Pharmacia LKB Biotechnology AB, Uppsala, Sweden). After centrifugation $(400 \times g$ for $30 \mathrm{~min}$ ), the lymphocytes were collected and washed twice with RPMI 1640 medium (Flow Laboratories, Irvine, Scotland). The final cell suspension (maximum $2 \times 10^{6}$ cells $/ \mathrm{mL}$ ) was made in RPMI 1640 medium containing 20\% FCS.

Antigen-specific immune response ( $A S S C$ ). For enumeration of $\beta$-lactoglobulin-sASC, Nunc Immunoplate (MaxiSorp, Nunc, Roskilde, Denmark) wells were coated $\left(2 \mathrm{~h}, 37^{\circ} \mathrm{C}\right)$ with $\beta$-lactoglobulin (Sigma) at a concentration of $20 \mu \mathrm{g} / \mathrm{mL}$ in PBS, pH 7.4. Uncoated binding sites were blocked with $1 \%$ BSA in PBS, $\mathrm{pH} 7.4\left(30 \mathrm{~min}, 37^{\circ} \mathrm{C}\right)$, after which the lymphocyte suspension was applied and incubated for 3 to $4 \mathrm{~h}$ at $37^{\circ} \mathrm{C}$. Alkaline phosphatase-conjugated sheep Ig to rat IgGAM (The Binding Site Limited, Birmingham, England) was diluted 1:500 or 1:1000 in $1 \%$ BSA-PBS and used for detecting the $\beta$-lactoglobulin-specific antibodies secreted by the rat lymphocytes. BCIP (5-bromo-4chloro-3-indolylphosphate p-toluidine salt; Sigma) was used as substrate for alkaline phosphatase in a solution of $2.9 \mathrm{mM}$ BCIP in $1 \mathrm{M}$ 2-amino-2-methyl-1-propanol buffer, $\mathrm{pH} 10.25$ (25), and it was applied in $0.6 \%$ agarose $\left(50^{\circ} \mathrm{C}\right)$. The working volume at each stage was $50 \mu \mathrm{L}$ per well. Between each incubation step, the wells were emptied and washed three times with PBS- $0.05 \%$ Tween, but before the cells were applied, the wells were washed with PBS. After various times of storage at $4^{\circ} \mathrm{C}$, spots were counted using a stereo microscope.

The numbers of sASC are expressed per $10^{6}$ cells plated. The small amount of blood available from rat pups did not allow determination of the isotype-specific immune responses.

Statistical Analysis. Because of skewed distribution, the HRP fluxes were transformed to their natural logarithms. Geometric means are presented with $95 \%$ confidence intervals. Two-tailed $t$ test and ANOVA with Tukey test were used in statistical comparisons.

\section{RESULTS}

Clinical data. As shown in Figure 1, weight gain during the experimental feeding period was comparable in the study groups. All groups infected with IDIR virus showed a somewhat slower rate of growth than the noninfected controls. At the time of the experiments on d 21, however, the mean weight gain achieved was identical in all groups. The duration of diarrhea as previously demonstrated is also shown (20).

Electron Microscopy. Electron microscopic investigation on d 
1 postinfection showed virus particles in dilated endoplasmic reticulum of epithelial cells (Fig. $2 A$ ) in all rats. Negative staining of fecal samples also confirmed the infection (Fig. $2 B$ ). At this stage, the adhesion of epithelial cells was intact (Fig. $3 A$ ).

In electron microscopic investigation at the age of $21 \mathrm{~d}$, cell junctions of the epithelium were closed (Fig. $3 B$ ). Neither virus particles nor dilation of intercellular spaces was present.

Electrical Parameters. The electrical parameters, PD, G, and $\mathrm{I}_{\mathrm{SC}}$ of the jejunal tissues of IDIR virus-infected controls are illustrated in Table 1 . PD and $I_{S C}$ were similar, whereas $G$ was elevated compared with noninfected controls. There were no further modifications of electrical parameters in the IDIR virusinfected pups gavaged with cow milk. The groups gavaged with the lactobacilli showed a lower $G$ than those not having received the lactobacilli, whereas $\mathrm{PD}$ and $\mathrm{I}_{\mathrm{SC}}$ remained comparable in all study groups.

ELISPOT Assay. Table 2 illustrates the frequency of sASC against $\beta$-lactoglobulin in all study groups. The observed statistically significant difference was attributable to elevated number of SASC in the two groups receiving cow milk, group CM and group CMGG, compared with the other study groups.

Intact HRP Absorption. The effect of the experimental infection on intestinal permeability was determined by comparing absorption of HRP in infected and noninfected controls at $21 \mathrm{~d}$ of age. The mean uptake rate of intact HRP was 8.7 times higher in the infected controls than in the noninfected controls (Table 2 ). To assess the duration of this effect of IDIR virus infection on intestinal permeability, infected controls were studied at $24 \mathrm{~d}$ of age. In these, the absorption of intact HRP, 32 (confidence interval 16,64$) \mathrm{ng} \times \mathrm{h}^{-1} \times \mathrm{cm}^{-2}$, was significantly decreased compared with 21 -d-old infected controls, but remained elevated compared with the level of noninfected controls $(t=1.99, p=$ 0.07).

The consequence of feeding cow milk to rat pups during the IDIR virus infection was an increase in the intact HRP absorption (Table 2). When comparing the four experimental feeding groups, a statistically significant association was demonstrated between the increase in intact HRP absorption and cow milk feedings $[F=4.42, p=0.04$ (two-way ANOVA)]. Introduction of the lactobacilli to the diet of rat pups was associated with a trend toward decreased intact HRP absorption $[F=3.64, p=$ 0.06 (two-way ANOVA)].

Degraded HRP Absorption. Figure 4 compares the absorption of degraded HRP in all study groups. The distinction between these was mainly attributable to the high uptake of degraded HRP in all IDIR virus-infected rat pups (Tukey test). Degraded HRP absorption was still elevated in infected controls at $24 \mathrm{~d}$ of age [10 250 (confidence interval 5570, 18863$\left.) \mathrm{ng} \times \mathrm{h}^{-1} \times \mathrm{cm}^{-2}\right]$ compared with noninfected controls $(t=2.40, p=0.04)$.

Feeding cow milk had no effect on the absorption of degraded HRP. The absorption of degraded HRP was lower in group GG and group $\mathrm{CMGG}$ compared with the other experimental feeding groups and not significantly different from the level of noninfected controls of the same age (Tukey test). The two-way ANOVA confirms this by demonstrating that a decrease in the uptake of degraded HRP was caused by administration of the lactobacilli $(F=9.50, p=0.004)$ irrespective of coexposure to cow milk.

\section{DISCUSSION}

The results of the present investigation confirm previous observations that rotavirus infection causes a dysfunction of the small intestinal mucosa (5-7). They further suggest that diet during diarrhea has a strong impact on the mucosal barrier functions.

The intestinal mucosa is the first line of host defense against antigens encountered by the enteric route (35). Most macromolecules are excluded by this barrier function. As recently reviewed by Heyman and Desjeux (36), antigens are absorbed by the intestinal epithelial cell mainly across a degradative pathway, implying the action of the intracellular lysosomal system. This pathway is not concerned with digestion and absorption of nutrients. The minor direct transcytosis pathway allows transport of intact proteins. In the present investigation, we found that the total ionic conductance, an index of the paracellular pathway, remained within physiologic limits during the Ussing chamber experiments (37). Cell adhesions were ultrastructurally unaltered. Thus, the modifications in the absorption of both intact and degraded HRP in the present study seem to reflect increased transcellular absorption. A recent study used human intestinal cell cultures infected with a species-nonspecific rhesus rotavirus and demonstrated loss of electrical resistance caused by an effect on the paracellular pathway (38). The fact that the dietary management independently influenced the uptake of intact and degraded HRP supports the previously proposed existence of the two functional pathways for transport of protein antigens across epithelial cells. The great interindividual differences in permeability are probably due to the necessarily small size of the mucosal sample that was studied, and the patchiness of the damage to the epithelium caused by the infection may have amplified this effect (2).

It has previously been shown (16-20) that rats are vulnerable to IDIR virus infection and diarrhea at the selected age of $10 \mathrm{~d}$, when gut closure is incomplete. To demonstrate the effect of rotavirus gastroenteritis on intestinal permeability, it was necessary to study age-matched, noninfected controls. An experimental study (6) on rotávirus-infected mice has previously shown that the increased intestinal permeability is transient, involving only the diarrheal phase of the infection, and that it is caused entirely by an increase in intact protein absorption. The mice were infected at an age when no developmental variations in macromolecular transport occur. In the present investigation, the absorption of both intact and degraded HRP were altered, and elevated gut permeability was still manifest at $24 \mathrm{~d}$ of age. Based on these results, it is suggested that the intestinal dysfunction caused by a rotavirus infection is more severe at this age of delicate modifications in the mucosal barrier.

In health, the usual consequence of feeding protein antigens is immunologic hyporesponsiveness (30), even though previous studies in infant mice have presented evidence that this may not be the case in the early postnatal period (39). Introduction of a new antigen, cow milk, to the diet during the experimental gastroenteritis amplified the small intestinal dysfunction. Initial contact with an antigen through a damaged epithelium may hence override induction of hyporesponsiveness and instead direct the antigen-specific response toward an immunoinflammatory reaction.

It is noteworthy that intestinal implantation of a Lactobacillus strain seemed to counteract the barrier dysfunction, as evidenced by a decreased intestinal permeability, and also a slightly lower conductance. This kind of stabilizing effect could be associated with normalization of the intestinal flora that is considered an important component of the gut mucosal barrier. It has actually been shown that the presence of microflora significantly alleviates the increase in macromolecular absorption during rotavirus gastroenteritis, as compared with germ-free animals (6). At present, it is unknown in what way the deliberate alteration of intestinal microflora by peroral lactobacilli may reinforce the mucosal barrier. Lactobacilli may produce antimicrobial substances or prevent the growth of pathogens by competition of either receptors or nutrients (14). They are able to potentiate gut immune defense $(13,14)$. It is possible that prerequisites for the production of these beneficial effects are the abilities to survive the gastric milieu and adhere to the intestinal epithelium, which are considered important colonization factors for these bacteria (40).

Applying results obtained in a rodent model to the human situation should be done cautiously. However, the results of this study are in concordance with our previous results in human infants (13), giving support to the idea that lactic acid bacteria 
that are able to colonize the gut even transiently provide protection against increased intestinal permeability and are useful in the treatment of acute diarrhea. Therefore, milk fermented with such bacteria may prove near-optimal nutrition for the nonbreast-fed infant during acute gastroenteritis.

Acknowledgments. The authors thank Dr. Steven L. Vonderfecht, Johns Hopkins University Medical School, for his gift of the IDIR virus, and Dr. Matti Lehtinen, Department of Virology, University of Tampere, for help in the preparation of the virus inoculum.

\section{REFERENCES}

1. Uhnoo I. Dharakul T. Riepenhoff-Talty M. Ogra PL 1988 Immunological aspects of interaction between rotavirus and the intestine in infancy. Immunol Cell Biol 66:135-145

2. Cohen MB 1991 Etiology and mechanisms of acute infectious diarrhea in infants in the United States. J Pediatr 188:S34-S39

3. Stern M. Pang KY. Walker WA 1984 Food proteins and gut mucosal barrier. II. Differential interactions of cow's milk proteins with the mucous coat and the surface membrane of adult and immature rat jejunum. Pediatr Res 18:1252-1257

4. Heyman M. Crain-Denoyelle AM. Desjeux JF 1989 Endocytosis and processing of protein by isolated villus and crypt cells of the mouse small intestine. J Pediatr Gastroenterol Nutr 9:238-245

5. Keljo DJ, Butler DG. Hamilton JR 1985 Altered jejunal permeability to macromolecules during viral enteritis in the piglet. Gastroenterology 88:998 1004

6. Heyman M. Corthier G. Petit A. Meslin JC. Moreau C. Desjeux JF 1987 Intestinal absorption of macromolecules during viral enteritis: an experimental study on rotavirus-infected conventional and germ-free mice. Pediatr Res 22:72-78

7. Jalonen T. Isolauri E. Heyman M. Crain-Denoyelle AM. Sillanaukee P. Koivula $\Upsilon 1991$ Increased $\beta$-lactoglobulin absorption during rotavirus enteritis in infants: relationship to sugar permeability. Pediatr Res 30:290-293

8. Flores J. Nakagomi O. Nakagomi T. Glass R. Gorziglia M. Askaa J, Hoshino Y. Perez-Schael I. Kapikian AZ 1986 The role of rotaviruses in pediatric diarrhea. Pediatr Infect Dis 5:S53-S62

9. Brown KH. MacLean WCJ 1984 Nutritional management of acute diarrhea: an appraisal of the alternatives. Pediatrics 73:119-125

10. Brown KH 1991 Dietary management of acute childhood diarrhea: optimal timing of feeding and appropriate use of milks and mixed diets. J Pediatr 118:S92-S98

11. Isolauri E. Vesikari T. Saha P. Viander M 1986 Milk versus no milk in rapid refeeding after acute gastroenteritis. J Pediatr Gastroenterol Nutr 5:254-261

12. Isolauri E. Juntunen M. Rautanen T. Sillanaukee P. Koivula T 1991 A human Lactobacillus strain (Lactobacillus casei sp strain GG) promotes recovery from acute diarrhea in children. Pediatrics 88:90-97

13. Kaila M. Isolauri E. Soppi E. Virtanen E. Laine S, Arvilommi H 1992 Enhancement of the circulating antibody secreting-cell response in human diarrhea by a human lactobacillus strain. Pediatr Res 32:141-144

14. Fuller R 1991 Probiotics in human medicine. Gut 32:439-442

15. Goldin BR. Gorbach SL. Saxelin M, Barakat S, Gualtieri L, Salminen S 1992 Survival of Lac/obacillus species (strain GG) in human gastrointestinal tract. Dig Dis Sci 37:121-128

16. Clarke RM. Hardy RN 1969 The use of $\left[{ }^{125}\right.$ I]polyvinyl pyrrolidone K.60 in the quantitative assessment of the uptake of macromolecular substances by the intestine of the young rat. J Physiol 204:113-125

17. Henning SJ 1987 Functional development of the gastrointestinal tract. In: Johnson LR (ed) Physiology of the Gastrointestinal Tract, 2nd Ed. Raven Press. New York, pp 285-300
18. Teichberg S, Isolauri E, Wapnir RA, Roberts B, Lifshitz F 1990 Development of the neonatal rat small intestinal barrier to nonspecific macromolecular absorption: effect of early weaning to artificial diets. Pediatr Res 28:31-37

19. Arvola T, Isolauri E, Rantala I, Kaila M, Virtanen E, Arvilommi H 1993 Increased in vitro intestinal permeability in suckling rats exposed to cow's milk during lactation. J Pediatr Gastroenterol Nutr (in press)

20. Vonderfecht SL, Eiden JJ, Miskuff RL, Yolken RH 1988 Kinetics of intestinal replication of group $B$ rotavirus and relevance to diagnostic methods. J Clin Microbiol 26:216-221

21. Markwell MA 1982 A new solid-state reagent to iodinate proteins. I. Conditions for the efficient labeling of antiserum. Anal Biochem 125:427-432

22. Maehly AC, Chance B 1954 The assay of catalases and peroxidases. In: Glick $\mathrm{D}$ (ed) Methods of Biochemical Analysis. Vol 1. Interscience Publishers Inc. New York, pp 357-398

23. Heyman M. Ducroc R, Desjeux JF, Morgat JL 1982 Horseradish peroxidase transport across adult rabbit jejunum in vitro. Am J Physiol 242:G558-G564

24. Czerkinsky CC, Nilsson LA. Nygren H, Ouchterlony Ö. Tarkowski A 1983 A solid-phase enzyme-linked immunospot (ELISPOT) assay for enumeration of specific antibody-secreting cells. J Immunol Methods 65:109-121

25. Sedgwick JD. Holt PG 1983 A solid-phase immunoenzymatic technique for the enumeration of specific antibody-secreting cells. J Immunol Methods 57:301-309

26. Mazer BD, Renz H, Gelfand EW 1991 An ELISA spot assay for quantitation of human immunoglobulin-secreting cells. J Allergy Clin Immunol 88:235243

27. Kantele A, Arvilommi H. Jokinen I 1986 Specific immunoglobulin-secreting human blood cells after peroral vaccination against Salmonella typhi. J Infect Dis 153:1126-1131

28. Forrest BD 1988 Identification of an intestinal immune response by using peripheral blood lymphocytes. Lancet 1:81-83

29. Isolauri E, Virtanen E, Jalonen T, Arvilommi H 1990 Local immune response measured in peripheral blood lymphocytes reflects the clinical reactivity of children with cow's milk allergy. Pediatr Res 28:582-586

30. Brandtzaeg P, Halstensen TS, Kett K, Krajci P, Kvale D. Rognum TO, Scott H, Sollid LM 1989 Immunobiology and immunopathology of human gut mucosa: humoral immunity and intraepithelial lymphocytes. Gastroenterology $97: 1562-1584$

31. McDermott MR, Bienenstock J 1979 Evidence for a common mucosal immunologic system. I. Migration of B immunoblasts into intestinal, respiratory, and genital tissues. J Immunol 122:1892-1898

32. Weisz-Carrington P. Roux ME, McWilliams M, Phillips-Quagliata JM Lamm ME 1979 Organ and isotype distribution of plasma cells producing specific antibody after oral immunization: evidence for a generalized secretory immune system. J Immunol 123:1705-1708

33. Kantele AM. Takanen R. Arvilommi H 1988 Immune response to acute diarrhea seen as circulating antibody-secreting cells. J Infect Dis 158:10111016

34. Keller SE, Schleifer SJ, McKegney FP, Sherman J, Camerino M. Stein M 1982 A simplified method for assessing PHA-induced stimulation of rat peripheral blood lymphocytes. J Immunol Methods 51:287-291

35. Walker WA 1986 Allergen absorption in the intestine: implication of food allergy in infants. J Allergy Clin Immunol 78:1003-1009

36. Heyman M. Desjeux JF 1992 Significance of intestinal protein transport. J Pediatr Gastroenterol Nutr 15:48-57

37. Heyman M, Corthier G, Lucas F. Meslin JC. Desjeux JF 1989 Evolution of the caecal epithelial barrier during Clostridium difficile infection in the mouse. Gut 30:1087-1093

38. Svensson L, Finlay BB, Bass D, von Bonsdorf CH. Greenberg HB 1991 Symmetric infection of rotavirus on polarized human intestinal epithelial (Caco-2) cells. J Virol 65:4190-4197

39. Strobel S, Ferguson A 1984 Immune responses to fed protein antigens in mice. 3. Systemic tolerance or priming is related to age at which antigen is first encountered. Pediatr Res 18:588-594

40. Tannock GW, Fuller R. Pedersen K 1990 Lactobacillus succession in the piglet digestive tract demonstrated by plasmid profiling. Appl Environ Microbiol 55:1848-1851 